\title{
Research and Exploration on the Process of mangosteen Compound Effervescent Tablets
}

\author{
ZIDAN MA ${ }^{1, *}$ \\ ${ }^{1}$ university of leeds(Leeds LS2 9JT United Kingdom )
}

\begin{abstract}
This article mainly studies a new type of compound effervescent tablet for hot pot soup base, which is made of mangosteen as the main material, adding mangosteen glycoside and kumquat to improve the taste, and adding starch slurry and PEG-6000 as a granulating agent. A single factor test was used to select the optimal level of each factor, the sensory score was used as the response value, and the response surface analysis method was used to optimize the formulation of the compound effervescent tablet, and the moisture absorption rate and sensory condition of the finished tablet after several days of placement were determined. The results showed that the optimized main formula of mangosteen compound effervescent tablets was: mangosteen powder $5.3 \%$, kumquat powder $1.3 \%$, mangosteen glycoside $1.3 \%$, effervescent disintegrant $90.7 \%$, of which citric acid: bicarbonate Sodium is $1.6: 1$. In this process, starch slurry and PEG-6000 are used as the granulation agent for the semi-dry tableting method. The composite effervescent tablet prepared after drying at $50^{\circ} \mathrm{C}$ for 3 hours is sweet and sour, rich in special aroma, short in foaming time, and has the lowest moisture absorption rate. The sensory score was 94.96 points.
\end{abstract}

\section{Introduction}

(A) The nutritional value and utilization of the main raw materials of compound effervescent tablets.

Mangosteen is a perennial deciduous cucurbitaceae plant, originally from Guangxi, China, and now mainly from tropical and subtropical mountains in China. The famous place of origin is Yongfu County, Guilin City. mangosteen has always enjoyed the reputation of "fairy fruit" for both medicine and food. It contains oleic acid, linoleic acid, dietary fiber, vitamin $\mathrm{C}$ and 26 trace elements. It can be used not only for the preparation of tonic soups and condiments, but also for medicinal purposes. Modern pharmacology proves that D-mannitol in mangosteen can relieve cough, its dehydration effect is stronger than urea and can increase blood osmotic pressure, and can be used for the treatment of cerebral edema.

mangosteen is rich in mangosteen glycosides, this ingredient is 300 times sweeter than sucrose, but unlike sucrose, mangosteen glycosides do not contain calories and have the effects of lowering blood sugar, blood fat, weight loss and intestinal tract, It can be used as an excellent substitute for sugar in food processing. The study found that Mogroside is insoluble in ethanol solution, and the amount of dissolution is greatly reduced with the increase of ethanol concentration ${ }^{[1]}$, so water should be used as a solvent to extract the glycoside. In addition, this effervescent tablet is specially designed for boiled base. The use of mogroside glycoside seasoning greatly reduces the heat of the soup base. It is suitable for beauties, diabetics and people who lose weight.

Kumquat is rich in aroma, contains vitamin $\mathrm{P}$, rich vitamin C, gankoside and other ingredients, can strengthen the microvascular elasticity, prevent blood vessel rupture, reduce capillary brittleness and permeability, prevent and cure arteriosclerosis, coronary heart disease, hypertension, etc. Disease has a positive effect ${ }^{[2]}$. Kumquat peel is sweet and sour, containing pectin, volatile oil, vitamins and so on. Not only is it rich in nutrition and unique in flavor, but also has various effects such as delaying aging, preventing pigmentation, regulating immunity, and lowering fat ${ }^{[3]}$.

(B) Research progress of effervescent tablets

Effervescent tablets are special tablets containing effervescent disintegrants. After encountering water, the acids and alkalis in them will chemically react and release a large amount of carbon dioxide to cause rapid disintegration. Solution, effervescent ${ }^{[3]}$. The effervescent disintegrant should be composed of a certain proportion of acid granules and alkali granules. The ratio of acid granules and alkali granules determines the foaming time of the effervescent tablet and the $\mathrm{pH}$ value of the tea soup after the effervescent tablet completely disintegrates. The binder is mainly used to bind the main raw materials and effervescent disintegrant, so that the tablet is uniform and stable, and the molding effect is better. Lubricants are

*corresponding author: ${ }^{\mathrm{a}}$ zhangjunzichen@163.com 
mainly used in the final step of tabletting. In order to obtain better lubrication effect, several lubricants are usually used in the food industry.

At present, there are few types of effervescent tablets produced by the food industry at home and abroad. It mainly produces and sells vitamin effervescent tablets, tea effervescent tablets and fruit and vegetable effervescent tablets. In recent years, honey, vitamins, fruit and vegetable juices have been added to effervescent tablets. It has become a trend to develop effervescent tablets with health care functions. However, most of the sweeteners commonly used in the effervescent tablet production industry, such as saccharin, cyclamate, stevia, etc., have been proved to have potential safety hazards ${ }^{[4]}$.

At present, research on mangosteen effervescent tablets is still in its infancy. According to the information and literature, only Xinglin Chuntang online pharmacy currently sells "Qingrun Yin" mangosteen effervescent tablets. Only Chen Bo, Chen Wei of Guilin Medical College and others developed a kind of mangosteen effervescent tablet, which did not add other functional and health-care raw materials. In summary, there is no research on mangosteen compound effervescent tablets, so the development of a mangosteen compound effervescent tablet has a very broad market space.

\section{The significance and innovation of the research purpose of this topic}

\section{(A) Research purpose}

The current hot pot has become an indispensable part of Chinese catering, and the type of hot pot base is relatively simple, mainly block butter base. However, its large volume and large mass are not easy to transport, and it will occupy a large amount of warehouse space during storage. In addition to a single type, which is not easy to store and transport, the bulk butter base has almost no health function and is not rich in nutrition. Therefore, the development of a sour and sweet flavored effervescent tablet containing a variety of beneficial nutrients is not only for traditional hot pot bottoms. The new improvement of the material form is another subversion of the traditional spicy hot pot base. In addition, the butter boiled base must be boiled with boiling water, customers need to wait for a long time to eat. Therefore, the development of a small pot size, lighter weight, easy to store and can meet the customer's rapid meal needs will be more in line with market demand.

\section{(B) Research significance}

To develop a new form of hot pot base material, so that it has a certain health function and effectively reduces the soup base heat, to achieve the purpose of health and not afraid of fat. For the seller, the effervescent tablet is convenient to store. When it is used, the effervescent tablet can be turned into warm soup or cold water to become a soup base, which greatly saves time and labor.

\section{(C) Innovations}

(1) Effervescent tablets have the characteristics of easy portability, good instant solubility, easy storage, and convenient drinking ${ }^{[4]}$, and can become a substitute for traditional bulk boiled bottom materials that are not easy to transport and easily deteriorate. However, its lighter weight and smaller volume can easily cause a lack of rich flavor and affect the taste of the hot pot soup. Therefore, extracting mogroside from the raw mangosteen and adding it to the effervescent tablet can not only improve the taste of the effervescent tablet, but also increase its sweetness. Degree, and solved the problem of hidden dangers of sweeteners.

(2) In order to make the effervescent tablet both functional and tasteful, the experiment added kumquat to balance the sweetness of mangosteen, while enriching the nutrition, researched and developed a hot and sour taste hot pot base, which became a favorite of sweet and sour soup base The new choice of customers really meets the requirements of healthy and functional hot pot.

(3) Since the added mogroside has no energy and is not easily absorbed by the body, it is used as a sweetener to effectively reduce the heat of the soup base, so that obese patients and diabetic patients can also eat hot pot with confidence.

(4) At present, there is no effervescent tablet that can be used as a hot pot base material and has a health function. The development of this effervescent tablet aims to enrich the variety of processed products of mangosteen, increase consumer choice, and increase the comprehensive development and utilization level of mangosteen.

\section{Materials and methods}

\subsection{Materials and reagents}

Mangosteen powder(first-grade)

Han Guo processed products factory

Kumquatpowder

Huitong Food and Beverage Factory

Luo Han Guo glycosides

to obtain

sodium bicarbonate (analytically pure)

Zhiyuan Chemical Reagent Co., Ltd.

Citric acid( analytically pure)

Zhiyuan Chemical Reagent Co., Ltd.

Corn starch(analysis pure)

Zhenlemen Food Co., Ltd.

extracted

Tianjin

Tianjin

Kunshan

\subsection{Instrument and equipment}

analysis balance BY101 Nanjing Su measurement and measurement instrument Co., Ltd.

pH meter pH808 Xima instrument sieve 20, 40 mesh zber/ Elephant Book Co., Ltd.

electric heating Constant Temperature Blast Dryer 202-00T Lichen Technology Co., Ltd.

Manual Tablet Press JR-16

Taizhou North America Machinery Co., Ltd. 


\subsection{Method} tablets

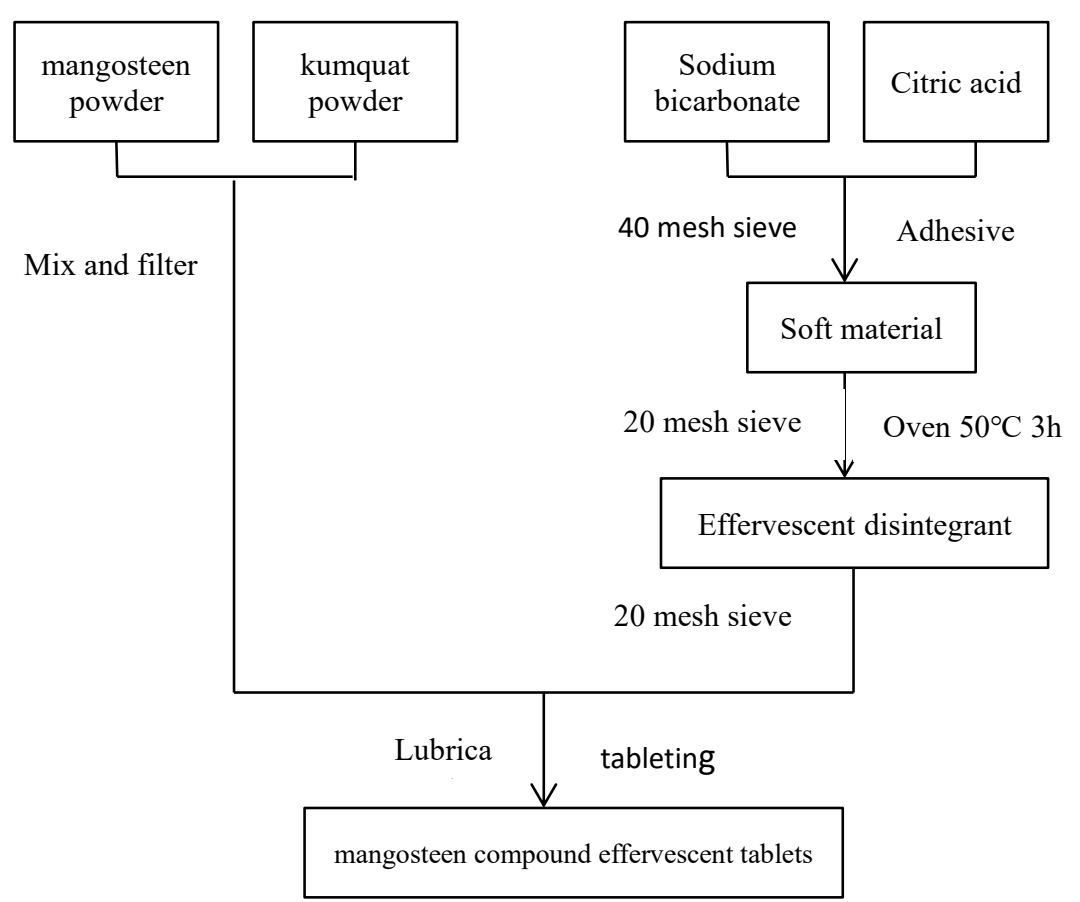

3.3.1 Preparation process of composite effervescent

\subsubsection{Study on the preparation of compound effervescent tablets}

\subsubsection{Study on the method of tabletting ${ }^{[4]}$}

Direct tableting method: Add $100 \%$ corn starch to the appropriate amount of Mangosteen powder and kumquat powder after 100 mesh sieve respectively The solution is mixed evenly and compressed into tablets.

Wet tableting method: Add 10\% concentration of corn starch solution to the soft mangosteen powder and kumquat powder to make soft materials, take out a 20 mesh sieve in an oven at $50^{\circ} \mathrm{C}$ for $3 \mathrm{~h}$, and press after granulation.

Semi-dry tableting method: $10 \%$ corn starch solution is added to the mixed and filtered mangosteen powder and kumquat powder, and the acid and alkali particles (sodium bicarbonate and citric acid) after 40 mesh sieve are made into soft The material is granulated through a 20 -mesh sieve and taken out in an oven at $50^{\circ} \mathrm{C}$ for 3 hours. After mixing the two granules, the granules are sieved again through a 20-mesh sieve, an appropriate amount of lubricant is added, and the tablets are compressed. See Table 5 for the influence of the above three common production methods on the properties of effervescent tablets and the final selection of production methods.

\subsubsection{Selection of granulating agents}

Lubricants and binders are common granulating agents for effervescent tablets. Lubricants can solve the problems of flaking and sticking during tableting, and should have good lubricity and water solubility ${ }^{[5]}$. The binder in the effervescent tablet should have good maneuverability, not easy to absorb moisture and good tablet solvent, which can meet the needs of people pursuing natural diet while achieving a good tableting effect ${ }^{[5]}$.

\subsubsection{Granulation drying test}

Take out the soft materials that have been dried at different temperatures for different times, determine and select the drying temperature and time that can make the moisture content of the acid and alkali particles reach a lower state. The test results are shown in Figure 1.

\subsubsection{Study on the formula of Mangosteen compound effervescent tablet}

\subsubsection{Single factor test of the addition of Mangosteen powder}

Weigh out the Mangosteen powder $0.08 \mathrm{~g}, 0.09 \mathrm{~g}, 0.10 \mathrm{~g}$, $0.11 \mathrm{~g}, 0.12 \mathrm{~g}$ (according to the weight of $1.5 \mathrm{~g}$ of each effervescent tablet as a standard) for 5 sets of single factor tests, to maintain the amount of kumquat powder $(0.02 \mathrm{~g})$, Mogroside $(0.02 \mathrm{~g})$, effervescent disintegrant $1.30 \mathrm{~g}$ (m sodium bicarbonate: $\mathrm{m}$ citric acid $=1: 1.6), 10 \%$ starch slurry $(0.01 \mathrm{~g})$, PEG-6000 $(0.01 \mathrm{~g})$ are all the same in the 5 groups of tests. The addition of Mangosteen powder is related to the difference in color of soup and 
precipitation, aroma and taste of the product.

Prepare the composite effervescent tablet according to the semi-dry compression method and mix it evenly with $100 \mathrm{ml}$ of cold boiling water. Select 10 people with the basis of sensory evaluation as sensory appraisers to adopt a 100-point system to determine the 3 levels required for the response surface test. Sensory score The standards are shown in Table 1, and the evaluation results are shown in Figure 2.

Table 1 Scoring standards of mangosteen tea soup

\begin{tabular}{|c|l|c|}
\hline \multicolumn{1}{|c|}{$\begin{array}{c}|c| \\
\begin{array}{c}\text { items } \\
\text { precipitation } \\
\text { (50 points) }\end{array}\end{array}$} & $\begin{array}{l}\text { Yellow, no precipitation } \\
\text { precipitation slightly }\end{array}$ & $39-50$ \\
\hline & $\begin{array}{l}\text { Light yellow, slightly } \\
\text { precipitation }\end{array}$ & $29-20$ \\
\hline & $\begin{array}{l}\text { Nearly colorless, no } \\
\text { precipitation }\end{array}$ & $19-10$ \\
\hline & $\begin{array}{l}\text { Appropriate taste with the } \\
\text { special smell of } \\
\text { Mangosteen }\end{array}$ & $40-50$ \\
\hline Flavor and taste \\
(50 points) & $\begin{array}{l}\text { Appropriate taste, slightly } \\
\text { sweet, with the special } \\
\text { smell of Mangosteen }\end{array}$ & $39-30$ \\
\hline & $\begin{array}{l}\text { Slightly sweet, with the } \\
\text { special smell of } \\
\text { Mangosteen }\end{array}$ & $29-20$ \\
\hline & $\begin{array}{l}\text { Too sweet, and the special } \\
\text { smell of kumquat is too } \\
\text { strong. }\end{array}$ & $19-10$ \\
\hline
\end{tabular}

\subsubsection{Single factor test of the addition of kumquat powder}

Weigh out the kumquat powder $0.01 \mathrm{~g}, 0.02 \mathrm{~g}, 0.03 \mathrm{~g}$, $0.04 \mathrm{~g}, 0.05 \mathrm{~g}$ (according to the weight of $1.5 \mathrm{~g}$ of each effervescent tablet as a standard) for 5 groups of single factor tests, to maintain the amount of Mangosteen powder $(0.08 \mathrm{~g}), \quad$ Mogroside $(0.02 \mathrm{~g})$, effervescent disintegrant $1.30 \mathrm{~g}$ ( $\mathrm{m}$ sodium bicarbonate: $\left.\mathrm{m}_{\text {citric acid }}=1: 1.6\right), 10 \%$ starch slurry $(0.01 \mathrm{~g})$, PEG-6000 $(0.01 \mathrm{~g})$ are all the same in the 5 groups of tests, and the addition of kumquat powder is related to the difference in color of soup and precipitation, aroma and taste of the product.

Prepare the composite effervescent tablet according to the semi-dry compression method and mix it evenly with $100 \mathrm{~mL}$ of cold boiling water. Select 10 people with the basis of sensory evaluation as sensory appraisers to adopt a 100-point system to determine the 3 levels required for response surface test and evaluation indicators. The standards are shown in table 2, and the evaluation results are shown in Figure 3.

Table 2 Scoring standards of Kumquat tea soup

\begin{tabular}{|c|l|c|}
\hline items & \multicolumn{1}{|c|}{ standards score } \\
\hline & $\begin{array}{l}\text { Light brown , no } \\
\text { precipitation }\end{array}$ & $40-50$ \\
\hline $\begin{array}{c}\text { Color of soup and } \\
\text { precipitation } \\
\text { (50 points) }\end{array}$ & $\begin{array}{l}\text { Light brown a small } \\
\text { amount of precipitation }\end{array}$ & $39-30$ \\
\hline & $\begin{array}{l}\text { Brown, a small amount of } \\
\text { precipitation }\end{array}$ & $29-20$ \\
\hline & Dark brown , a large & $19-10$ \\
\hline
\end{tabular}

\begin{tabular}{|c|l|c|}
\hline & amount of precipitation & \\
\hline & $\begin{array}{l}\text { Appropriate taste with the } \\
\text { special smell of kumquat }\end{array}$ & $40-50$ \\
\hline $\begin{array}{c}\text { Flavor and taste } \\
\text { (50 points) }\end{array}$ & $\begin{array}{l}\text { Appropriate taste, slightly } \\
\text { sour, with the special smell } \\
\text { of kumquat }\end{array}$ & $39-30$ \\
\hline & $\begin{array}{l}\text { Sour, and the special smell } \\
\text { of kumquat is too strong }\end{array}$ & $29-20$ \\
\hline & $\begin{array}{l}\text { No sour taste, almost no } \\
\text { special odor of kumquat }\end{array}$ & $19-10$ \\
\hline
\end{tabular}

\subsubsection{Single factor test of the proportion of effervescent disintegrantln}

Sodium bicarbonate was mixed with different amounts of citric acid, that is, $\mathrm{m}$ citric acid: $\mathrm{m}$ sodium bicarbonate $=$ $0.8 \sim 2.0,5$ groups of single factor test were conducted, and the addition of Mangosteen powder $(0.08 \mathrm{~g})$, kumquat powder $(0.02 \mathrm{~g})$, mogroside $(0.02 \mathrm{~g}), 10 \%$ starch slurry $(0.01 \mathrm{~g})$,PEG-6000 $(0.01 \mathrm{~g})$ are all the same in 5 groups of test. The proportion of effervescent disintegrant related to the difference in foaming time and $\mathrm{pH}$.

Determination of foaming time: Dissolve the effervescent tablet $(1.5 \mathrm{~g})$ in $100 \mathrm{~mL}$ of $55^{\circ} \mathrm{C}$ water, start timing when the effervescent tablet is placed in water, and stop timing when the bubbles stop releasing. The foaming time is the average value of 6 finished tablets tested in parallel ${ }^{[11]}$

Determination of $\mathrm{pH}$ : According to the Chinese Pharmacopoeia Appendix XIH ${ }^{[12]}$. After the effervescent tablet is placed in water, the bubbles stop releasing, the tablet dissolves and disperses in the water, and $\mathrm{pH}$ is measured when there are no aggregated or residual particles in the water.

Prepare the composite effervescent tablet according to semi-dry tableting method and mix it evenly with 100 $\mathrm{mL}$ of cold boiled water to determine 3 levels that the foaming time is short and stable, $\mathrm{pH}$ is suitable to conduct the response surface test. The results are shown in Figure 4.

\subsubsection{Single factor test of the addition of mogroside}

Using water as a solvent, Mangosteen powder was extracted and calcium hydroxide was added to clarify the crude extract of Mangosteen glycoside ${ }^{[6]}$.

Weighed the mogroside $0.00 \mathrm{~g}, 0.01 \mathrm{~g}, 0.02 \mathrm{~g}, 0.03 \mathrm{~g}$, $0.04 \mathrm{~g}$ for 5 sets of single factor test, keeping the Mangosteen powder $(0.08 \mathrm{~g})$, kumquat powder $(0.02 \mathrm{~g})$, effervescent disintegrant $1.30 \mathrm{~g}$ ( $\mathrm{m}$ sodium bicarbonate: $\mathrm{m}$ citric acid $=1: 1.6), 10 \%$ starch slurry $(0.01 \mathrm{~g})$, PEG-6000 (0.01g) same in 5 tests.

Prepare the compound effervescent tablet by semi-dry tableting method and mix it with $100 \mathrm{~mL}$ of cold water evenly. Select 10 people with the basis of sensory evaluation skills as sensory appraisers and adopt 100 -point system to choose three appropriate levels of $\mathrm{pH}$ and sensory scores. Using these figures to build a 
response surface test. The results are shown in Figure 5.

\subsubsection{Response surface test}

According to the results of single factor test, the addition of Mangosteen powder, the amount of kumquat powder, the proportion of effervescent disintegrant and the amount of Mangosteen glycoside were selected as independent variables, and the optimal level of each factor was selected, and the sensory score was used as the response.In response, the main ingredients of the compound effervescent tablets (the amount of Mangosteen powder, the amount of kumquat powder, the proportion of effervescent disintegrant, the amount of Mangosteen glycoside) were optimized by response surface analysis. The factors and level design of response surface analysis are shown in Table 3.

Table 3 analysis from response surface

\begin{tabular}{|c|c|c|c|c|}
\hline Level & $\begin{array}{c}\text { A addition } \\
\text { of } \\
\text { Mangoste } \\
\text { en } \\
\text { powder } / \mathrm{g}\end{array}$ & $\begin{array}{c}\mathrm{B} \\
\text { addition } \\
\text { of } \\
\text { kumquat } \\
\text { powder } \\
/ \mathrm{g}\end{array}$ & $\begin{array}{c}\mathrm{C} \text { proportion } \\
\text { of } \\
\text { effervescent } \\
\text { disintegrant }\end{array}$ & $\begin{array}{c}\mathrm{D} \text { addition } \\
\text { of } \\
\text { mogroside } \\
/ \mathrm{g}\end{array}$ \\
\hline-1 & 0.08 & 0.02 & $1: 1.6$ & 0.01 \\
\hline 0 & 0.09 & 0.03 & $1: 1.7$ & 0.02 \\
\hline 1 & 0.10 & 0.04 & $1: 1.8$ & 0.03 \\
\hline
\end{tabular}

\subsubsection{Inspection the quality of effervescent tablets}

\subsubsection{Determination of moisture absorption rate of composite effervescent tablets}

The three groups of composite effervescent tablets which selected for the response surface test were prepared and wrapped in tin foil, placed in a plastic packaging bucket (the same as plastic packages of effervescent tablets in the market now), and stored at room temperature. After $12 \mathrm{~h}, 24 \mathrm{~h}, 36 \mathrm{~h}, 48 \mathrm{~h}, 60 \mathrm{~h}$ the moisture absorption rate is determined according to the following formula.

Moisture absorption rate $=\mathrm{M} 1-\mathrm{M} 0 / \mathrm{M} 0$; (where $\mathrm{M} 0$ is the quality of the effervescent tablet dried to constant weight, and M1 is the quality of the effervescent tablet after being placed for $12 \mathrm{~h}, 24 \mathrm{~h}, 36 \mathrm{~h}, 48 \mathrm{~h}, 60 \mathrm{~h}$ according to the above standard).

The results are shown in Figure 11.

\subsubsection{Sensory score}

Composite effervescent tablets stored at room temperature for several days were dissolved in water and subjected to sensory evaluation ${ }^{[7-9]}$. Select 10 people with the basis of sensory evaluation skills as sensory appraisers and adopt a 100-point system. Sensory standards and score are in table4.

Table 4 Sensory evaluation criteria for the quality of effervescent tablets

\begin{tabular}{|c|c|c|c|c|c|}
\hline items & \multicolumn{4}{|c|}{ standard } & score \\
\hline & The & sour & $\mathrm{o}$ & comnound & $15-20$ \\
\hline
\end{tabular}

\begin{tabular}{|c|c|c|}
\hline & $\begin{array}{l}\text { effervescent tablets is bright } \\
\text { Brownish yellow, close to the } \\
\text { color of mangosteen }\end{array}$ & \\
\hline \multirow[t]{3}{*}{ Color } & $\begin{array}{l}\text { Light brownish-yellow with } \\
\text { darker color }\end{array}$ & $5-15$ \\
\hline & Almost colorless, dull color & $<5$ \\
\hline & $\begin{array}{l}\text { No precipitation, stable and } \\
\text { uniform, clear, no impurities }\end{array}$ & $15-20$ \\
\hline \multirow[t]{3}{*}{$\begin{array}{l}\text { Organizational } \\
\text { status }\end{array}$} & $\begin{array}{l}\text { A small amount of precipitation, } \\
\text { more stable and uniform, with } \\
\text { layers, without impurities }\end{array}$ & $5-15$ \\
\hline & $\begin{array}{l}\text { A large amount of precipitation, } \\
\text { with obvious stratification and no } \\
\text { impurities }\end{array}$ & $<5$ \\
\hline & $\begin{array}{l}\text { Has a strong aroma of } \\
\text { mangosteen, no odor }\end{array}$ & $20-30$ \\
\hline \multirow[t]{3}{*}{ Flavor } & $\begin{array}{l}\text { It has the aroma of mangosteen, } \\
\text { which is slightly light, smelly but } \\
\text { not obvious }\end{array}$ & $5-20$ \\
\hline & $\begin{array}{l}\text { No Mangosteen aroma or lack of } \\
\text { aroma, with obvious odor }\end{array}$ & $<5$ \\
\hline & $\begin{array}{l}\text { Moderate sour and sweet, } \\
\text { mangosteen has a clear flavor, } \\
\text { delicate and not sweet }\end{array}$ & $20-30$ \\
\hline \multirow[t]{2}{*}{ Taste } & $\begin{array}{l}\text { Slightly sweet, the fragrance of } \\
\text { mangosteen is slightly weak }\end{array}$ & $5-20$ \\
\hline & $\begin{array}{l}\text { Sour, the fragrance of } \\
\text { mangosteen is slightly weak }\end{array}$ & $<5$ \\
\hline
\end{tabular}

\section{Results and analysis}

\subsection{Research results of compound effervescent tablet preparation}

\subsubsection{Selection of LuoHanGuo compound effervescent tablet preparation method}

Effervescent tablets need to be made into tablets in an appropriate way, and the choice of preparation method will affect its various Properties, such as: sieving before soft, viscous, dissolving, moisture absorption, precipitation, particle fluidity, etc.

Table 5 The effect of tabletting on effervescent tablets

\begin{tabular}{|l|l|l|l|}
\hline items & $\begin{array}{l}\text { Direct } \\
\text { tableting }\end{array}$ & $\begin{array}{l}\text { Wet } \\
\text { tableting }\end{array}$ & $\begin{array}{l}\text { Semi-dry } \\
\text { tableting }\end{array}$ \\
\hline $\begin{array}{l}\text { Soft material } \\
\text { sieving }\end{array}$ & easy & not easy & easy \\
\hline viscous impact & yes & yes & no \\
\hline dissolution & easy & not easy & easy \\
\hline $\begin{array}{l}\text { moisture } \\
\text { absorption }\end{array}$ & easy & not easy & not easy \\
\hline precipitation & $\begin{array}{l}\text { large } \\
\text { amount }\end{array}$ & $\begin{array}{l}\text { large } \\
\text { amount }\end{array}$ & $\begin{array}{l}\text { Small } \\
\text { amount of or } \\
\text { no }\end{array}$ \\
\hline $\begin{array}{l}\text { particle } \\
\text { mobility }\end{array}$ & good & bad & bad \\
\hline
\end{tabular}

From the above table analysis, it can be seen that although the direct compression method has the advantages of simple and easy to practice, the tablets formed by this method have more precipitation after dissolution. Wet tableting separates acid granules and alkali granules in the process, to a certain extent, it 
effectively avoids the instability of the finished product caused by the reaction of acid granules and alkali granules, but this method produces a large amount of precipitation after the effervescent tablet dissolves. Affects the taste. The semi-dry tableting method has the advantages of easy sieving, not easy to absorb moisture and almost no precipitation, so the production of the composite effervescent tablet should be carried out using the semi-dry tableting method.

\subsubsection{Selection of granules of Luo Han Guo compound effervescent tablets}

Consult the data to see that commonly used tablet lubricants include PEG-6000, L-leucine, sodium stearyl fumarate (potassium), sodium lauryl sulfate (magnesium), Micronized silica gel, etc. L-leucine has a good lubricating effect on effervescent tablets, but its price is high ${ }^{[10]}$. The micropowder silica gel is insoluble in water due to its own properties, and forms an oil film, which greatly reduces the sensory quality. Therefore, PEG-6000 is used as a lubricant in the process of acid granulation and alkali granulation, but PEG-6000 has the problem of low melting point, so the addition amount should not exceed $5 \%$ of the total weight of the finished tablet.

The binders commonly used in effervescent tablets, such as maltodextrin and hypromellose, are solid particles, which are easy to absorb moisture after being added. Therefore, corn starch slurry was selected as the composite effervescent tablet binder in the test, which is in line with people's pursuit of diet At the same time, the natural demand has reached a good production effect.

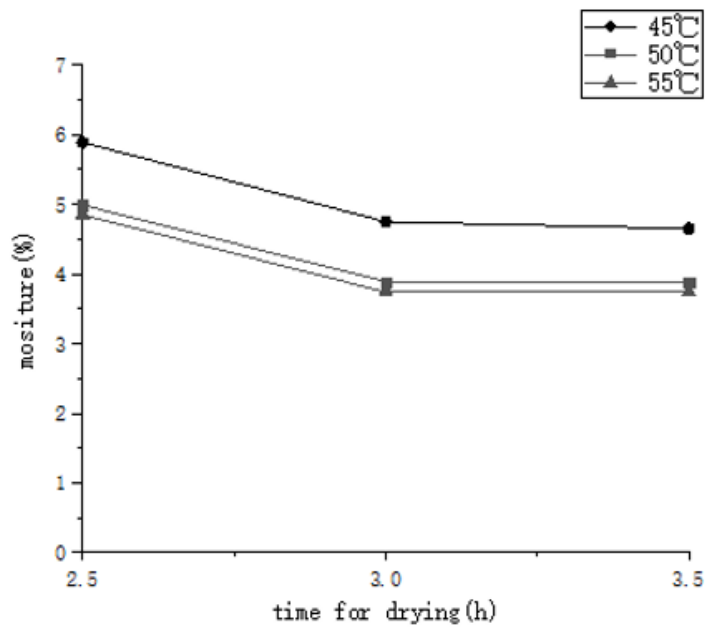

Figure 1 conclusion of drying experiment

It can be seen from the analysis in Figure 1 that when the drying temperature is 50 and $55^{\circ} \mathrm{C}$, the constant weight is reached after drying for 3 hours. The moisture content decreased slightly after drying for 3 hours at $45^{\circ} \mathrm{C}$, but the difference between the moisture content after drying for 3 hours and 3.5 hours was small. In order to save costs and reduce energy consumption, the drying temperature is $50{ }^{\circ} \mathrm{C}$ for 3 hours and granulation can achieve the effect of lower moisture content.

\subsection{Research results of the formulation of Mangosteen compound effervescent tablets}

\subsubsection{Effect of Mangosteen powder addition on sensory evaluation}

To investigate the effect of sensory quality on different Mangosteen powder addition, the assessment results are shown in Figure 6.

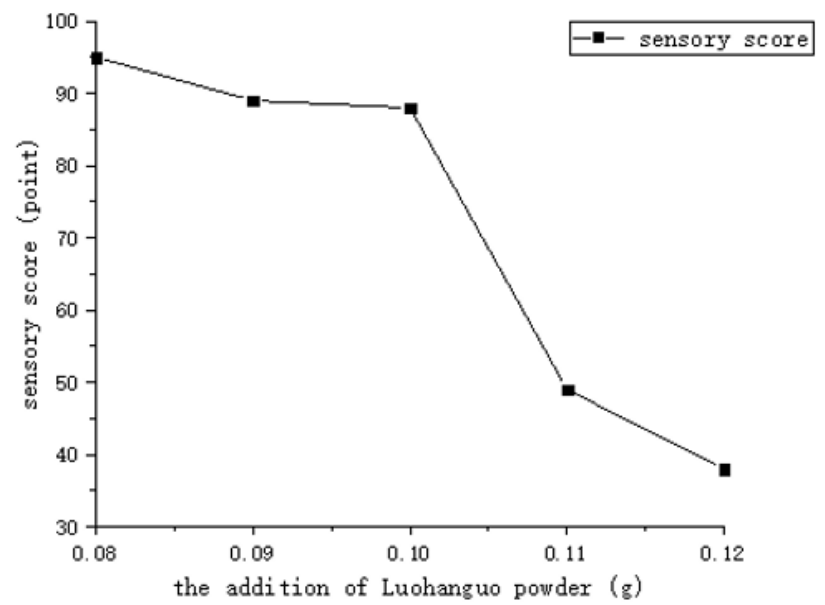

Figure 2 The effect on sensory evaluation of mangosteen Powder

It can be seen from Fig. 2 that as the amount of Mangosteen powder increases, the sensory score of the tea soup gradually decreases. When the amount of Mangosteen powder is $0.08 \sim 0.10 \mathrm{~g}$, the tea soup is light brown, no precipitation and rich aroma of Mangosteen , but when the amount of mangosteen powder exceeds $0.10 \mathrm{~g}$, the tea soup is dark brown and produces a small amount of insoluble precipitate, tea soup Excessive sweetness affects sensory quality. Therefore, considering comprehensively, selecting $0.08 \sim 0.10 \mathrm{~g}$ of LuoHanGuo powder into $100 \mathrm{~mL}$ of water has a high sensory score, so $0.08 \mathrm{~g}, 0.09 \mathrm{~g}$, and $0.10 \mathrm{~g}$ were selected for response surface test. (According to the quality of Luo Han Guo powder accounted for the quality of each compound effervescent tablet as the standard)

\subsubsection{The effect of the amount of kumquat powder added on the sensory evaluation}

The effect of sensory quality on the amount of kumquat powder added was investigated. The evaluation results are shown in Table 7. 


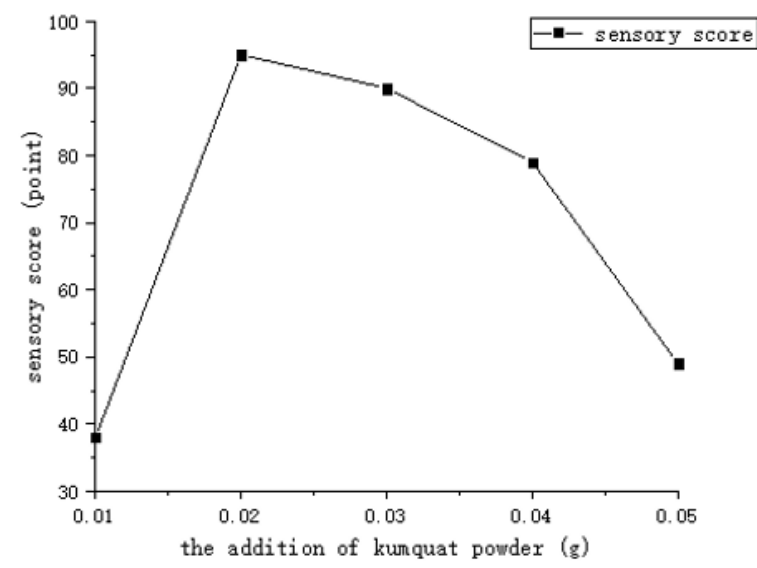

Figure 3 The effect on sensory evaluation of kumquat Powder

It can be seen from Figure 3 that as the amount of kumquat powder added increases, the sensory score of the tea soup increases first and then decreases. When the added amount is less than $0.02 \mathrm{~g}$, the kumquat aroma of the tea soup is insufficient, and there is almost no sour taste, while when the added amount of kumquat powder is $0.02 \sim 0.04 \mathrm{~g}$, the tea soup is yellow, no precipitation or a small amount of precipitation and rich kumquat aroma, but When the amount of kumquat powder added exceeds $0.04 \mathrm{~g}$, the color of the tea soup becomes darker, and the acidity is too large to affect the sensory quality. Therefore, considering the above, 0.02-0.04 $\mathrm{g}$ of kumquat powder was added to $100 \mathrm{~mL}$ of water to have a higher sensory score, so $0.02 \mathrm{~g}, 0.03 \mathrm{~g}$, and $0.04 \mathrm{~g}$ were selected for response surface test. (According to the quality of kumquat powder accounting for the quality of each compound effervescent tablet as the standard)

\subsubsection{Single factor test results of the ratio of effervescent disintegrant}

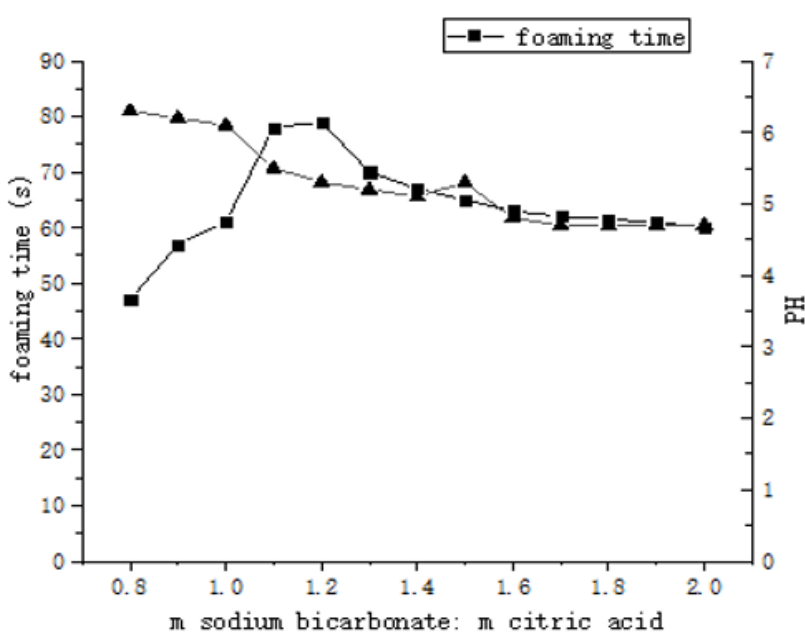

Figure 4 foaming time and $\mathrm{pH}$ effected by proportion of effervescent disintegrant

It can be seen from Fig. 4 that as the content of citric acid in the effervescent agent increases, the $\mathrm{pH}$ value slowly decreases, reaching a stable state when $\mathrm{m}$ citric acid: $\mathrm{m}$ sodium bicarbonate $=1.6$, and its $\mathrm{pH}$ stabilizes at about 4.2. The foaming time increases first and then decreases as the content of citric acid in the effervescent agent increases. It can be seen from the figure that when the mass ratio of the effervescent agent is 1.1 to 1.2 , the foaming is longer, and the foaming time is the longest at 1.2. After 1.3 , the foaming time decreases slightly and then stabilizes at about $60 \mathrm{~s}$. At this time, $\mathrm{m}$ citric acid: $\mathrm{m}$ Sodium hydrogen $=1.6$. Therefore, combining two indicators, choose $\mathrm{m}$ citric acid: $\mathrm{m}$ sodium bicarbonate $=1.6,1.7$, 1.8 for response surface test.

\subsubsection{Effect of Mogroside on the sensory evaluation}

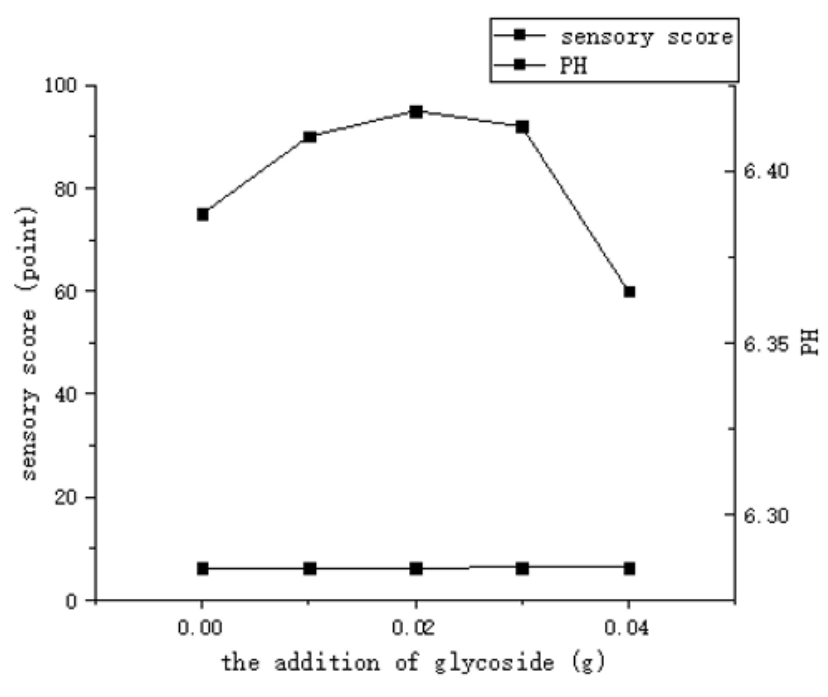

Figure 5 The effect on sensory evaluation of glycoside

It can be seen from Figure 5 that the addition of mogrosides has little effect on the $\mathrm{pH}$ of the tea soup after the effervescent tablet is completely disintegrated, but it has a greater impact on the sensory score. From the above figure, the sensory score of the tea soup with the amount of glycoside added first rises When it is high, it decreases, and when no glycoside is added, the acidity of the tea soup is large. When the amount of sweet glycoside is $0.01 \sim 0.03 \mathrm{~g}$, the tea soup is sweet and sour, and the sensory score is higher. When the amount of added glycoside exceeds $0.03 \mathrm{~g}$, the tea soup is too sweet, resulting in a decrease in sensory score. Therefore, the addition amount of sweet glycoside is $0.01 \mathrm{~g}, 0.02 \mathrm{~g}$, $0.03 \mathrm{~g}$ for response surface test.

\subsubsection{Analysis of the response surface test results}

The sensory score of the tablet is used as the response value, and the sensory score is regression fitted with Design-Expert 8.0.6 to optimize the process of the composite effervescent tablet to determine the optimal amount of each raw material. . The regression results of the four dependent variables with the sensory score as the response value (A)Luo han guo power, (B) kumquat powder, (C)effervescent disintegrant, (D)mogroside .The equation of regression is:

$\mathrm{Y}=91.75-0.87 \mathrm{~A}-2.00 \mathrm{~B}-0.33 \mathrm{C}+0.21 \mathrm{D}+0.12 \mathrm{CD}+0.65 \mathrm{~A}^{2}-0$. $73 \mathrm{~B}^{2}+0.083 \mathrm{C}^{2}-1.04 \mathrm{D}^{2}$

Table 6 model of regression

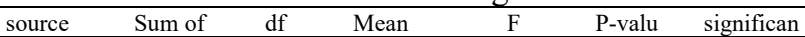




\begin{tabular}{|c|c|c|c|c|c|c|}
\hline & squares & & square & value & $\begin{array}{c}\mathrm{e} \\
\text { Prob }> \\
\mathrm{F}\end{array}$ & $\mathrm{t}$ \\
\hline model & 74.22 & $\begin{array}{l}1 \\
4\end{array}$ & 5.30 & 705.32 & $\underset{0.0001}{<}$ & $* *$ \\
\hline A & 9.15 & 1 & 9.15 & $\begin{array}{c}1217.6 \\
3\end{array}$ & $\begin{array}{c}< \\
0.0001\end{array}$ & $* *$ \\
\hline B & 47.92 & 1 & 47.92 & $\begin{array}{c}6375.1 \\
7\end{array}$ & $\begin{array}{c}< \\
0.0001\end{array}$ & $* *$ \\
\hline $\mathrm{C}$ & 1.31 & 1 & 1.31 & 173.85 & $\begin{array}{c}< \\
0.0001\end{array}$ & $* *$ \\
\hline D & 0.52 & 1 & 0.52 & 69.29 & $\begin{array}{c}< \\
0.0001\end{array}$ & $* *$ \\
\hline $\mathrm{AB}$ & $\begin{array}{c}1.000 \mathrm{E}-00 \\
4\end{array}$ & 1 & $\begin{array}{c}1.000 \mathrm{E}-00 \\
4\end{array}$ & 0.013 & 0.9098 & \\
\hline $\mathrm{AC}$ & $\begin{array}{c}1.000 \mathrm{E}-00 \\
4\end{array}$ & 1 & $\begin{array}{c}1.000 \mathrm{E}-00 \\
4\end{array}$ & 0.013 & 0.9098 & \\
\hline $\mathrm{AD}$ & 0.000 & 1 & 0.000 & 0.000 & 1.0000 & \\
\hline BD & 0.000 & 1 & 0.000 & 0.000 & 1.0000 & \\
\hline $\mathrm{CD}$ & 0.063 & 1 & 0.063 & 8.31 & 0.0120 & $*$ \\
\hline $\mathrm{A}^{2}$ & 2.69 & 1 & 2.69 & 358.08 & $\begin{array}{c}< \\
0.0001\end{array}$ & $* *$ \\
\hline$B^{2}$ & 3.44 & 1 & 3.44 & 457.77 & $\begin{array}{c}< \\
0.0001\end{array}$ & $* *$ \\
\hline $\mathrm{C}^{2}$ & 0.041 & 1 & 0.041 & 5.41 & 0.0356 & $*$ \\
\hline $\mathrm{D}^{2}$ & 7.06 & 1 & 7.06 & 939.36 & $\begin{array}{c}< \\
0.0001\end{array}$ & $* *$ \\
\hline $\begin{array}{c}\text { residua } \\
1\end{array}$ & 0.11 & $\begin{array}{l}1 \\
4\end{array}$ & $\begin{array}{c}7.517 \mathrm{E}-00 \\
3\end{array}$ & & & \\
\hline $\begin{array}{c}\text { Lack of } \\
\text { fit }\end{array}$ & 0.11 & $\begin{array}{l}1 \\
0\end{array}$ & 0.011 & 5.75 & 0.0822 & \\
\hline $\begin{array}{l}\text { Pure } \\
\text { error }\end{array}$ & 0.000 & 4 & 0.000 & & & \\
\hline $\begin{array}{l}\text { Cor } \\
\text { total }\end{array}$ & 74.33 & $\begin{array}{l}2 \\
8\end{array}$ & & & & \\
\hline
\end{tabular}

Note: The investigation factors have significant influences indicated by $*(\mathrm{P}<0.05)$, and extremely significant influences indicated by $* *(\mathrm{P}<0.01)$

The variance (table) of the regression model can be seen: $\mathrm{P}<0.0001$ of LuoHanGuo compound effervescent tablet model, regression The effect is extremely significant, and the process parameters can be effectively predicted. At the same time, A, B, C, and D all had a significant effect on the sensory score of LuoHanGuo compound effervescent tablets $(\mathrm{P}<0.01), \quad \mathrm{P}>0.05$ indicated that $\mathrm{AB}, \mathrm{AC}, \mathrm{BC}$, and $\mathrm{BD}$ had no significant effect on the sensory score of effervescent tablets. $\mathrm{P}<0.05$ indicates that $\mathrm{CD}$ has a significant effect on the sensory score of effervescent tablets. A ${ }^{2}$. $\mathrm{B}^{2}$ has a very significant effect on the sensory score of the compound effervescent tablet $(\mathrm{P}<0.01) . \mathrm{C}^{2}$ has a significant effect on the sensory score of the compound effervescent tablet
$(\mathrm{P}<0.05)$. The effect of the film is not a simple linear relationship [13].

After obtaining the above response surface analysis, use Design-Expert 8.0.6 software to optimize the prediction of the regression model. The prediction results are as follows: $\mathrm{A}=0.08 \mathrm{~g}, \mathrm{~B}=0.02 \mathrm{~g}, \mathrm{C}=1: 1.6, \mathrm{D}=0.02 \mathrm{~g}$, that is Luo Han Guo powder The added amount was 0.08 $\mathrm{g}$, the added amount of kumquat powder was $0.02 \mathrm{~g}$, and the ratio of effervescent disintegrant was 1:1.6. At this time, the response value (sensory score) obtained was the largest at 94.96 points.

Repeatedly using this formula to make Luo Han Guo composite effervescent tablets three times, the average sensory score was 94.5 points, which was not much different from the theoretical predicted value of 94.96 points, indicating that the model had small errors, reliable results and practical application value.

\subsubsection{Interaction analysis}

In the response surface diagram, the contour shape can simply and clearly reflect the strength of the interaction between the two factors (ie, the two main raw materials). When the contour is elliptical or saddle-shaped, the interaction between the two dependent variables is strong, and when the contour is circular, the interaction between the two dependent variables is weak [14]. The contours and response surface diagrams of the interaction of main raw materials are shown in Figures 6-11.

As shown in the response surface diagram, with the gradual increase of the two dependent variable values, the sensory score of LuoHanGuo compound effervescent tablets will gradually increase, but when the two dependent variables reach a certain value combination, the sensory score will show a decline Trend, this value is called the highest point of the response surface [15]. The response surface of factor $\mathrm{A}$ and factor $\mathrm{D}$ is convex, and the contour is saddle-shaped, indicating that the amount of Mangosteen powder and the amount of Mangosteen glycoside have a significant interaction. The interaction between other factors $(\mathrm{AB}, \mathrm{AC}, \mathrm{BC}, \mathrm{BD}, \mathrm{CD})$ was not significant.
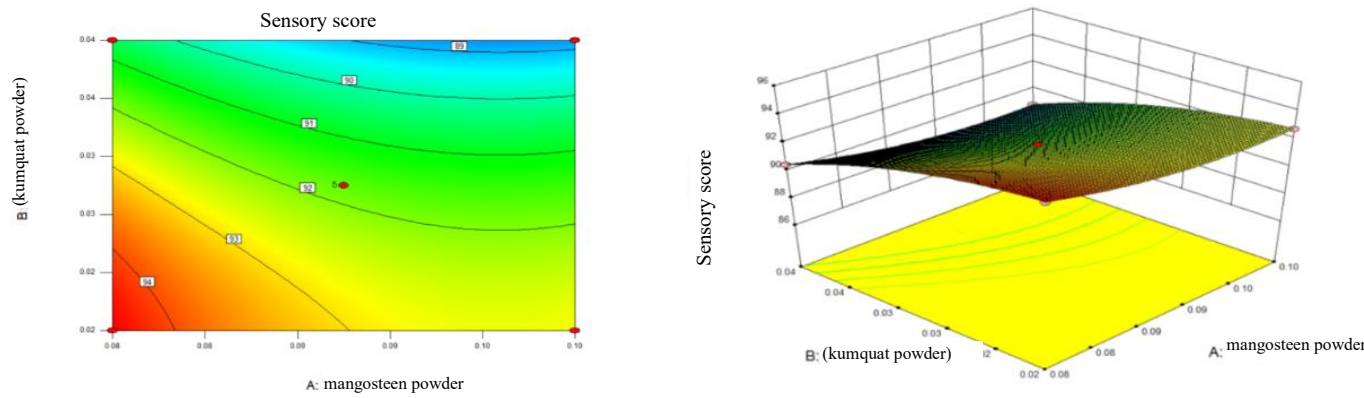

Figure 6 Contour and response surface diagram of the effect of the interaction between the amount of mangosteen powder and the amount of kumquat powder on the sensory score 

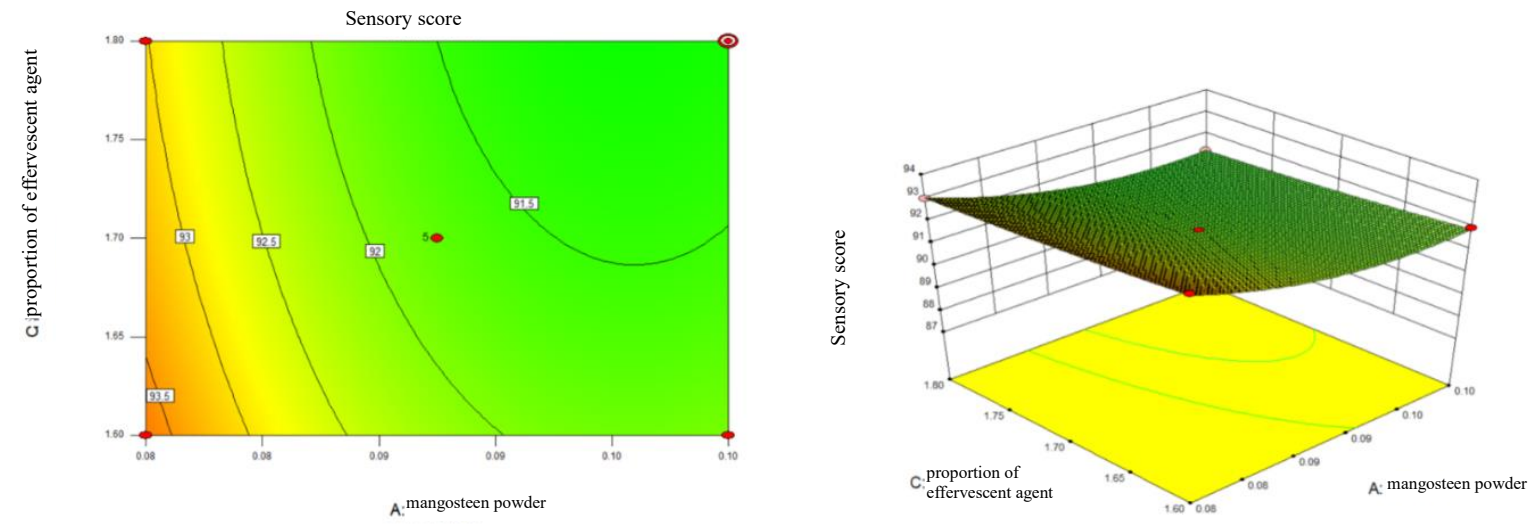

Figure 7 Contour diagram and response surface diagram of the effect of the interaction between the amount of mangosteen powder and the proportion of effervescent agent on the sensory score
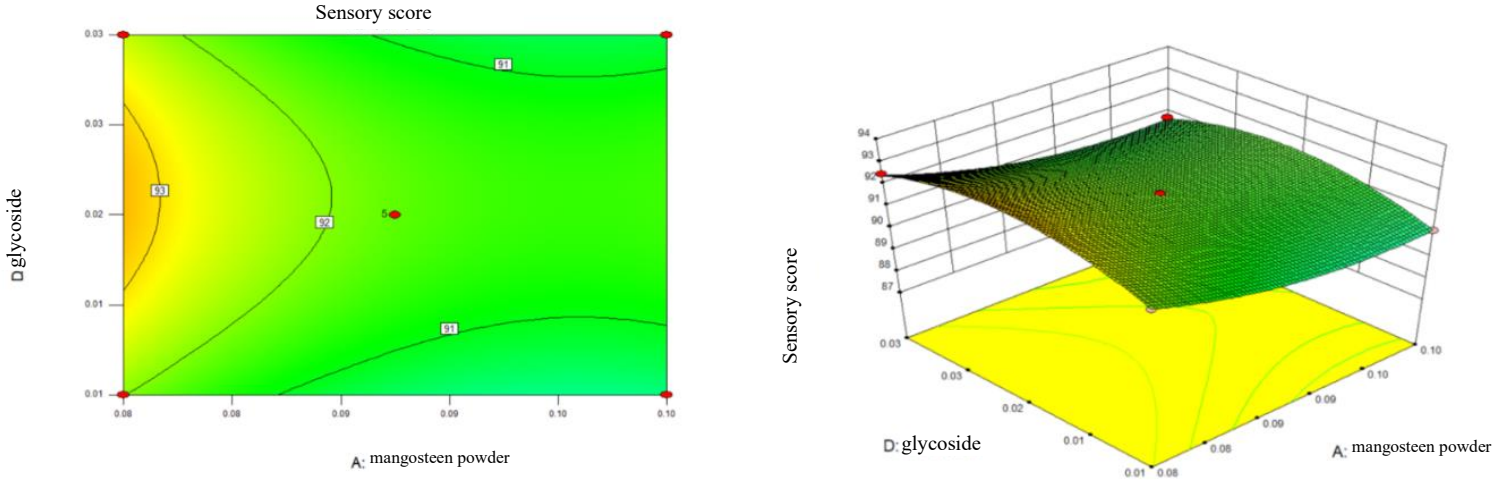

Figure 8 Contour and response surface diagrams of the effect of the interaction of mangosteen powder and mangosteen glycoside on the sensory score
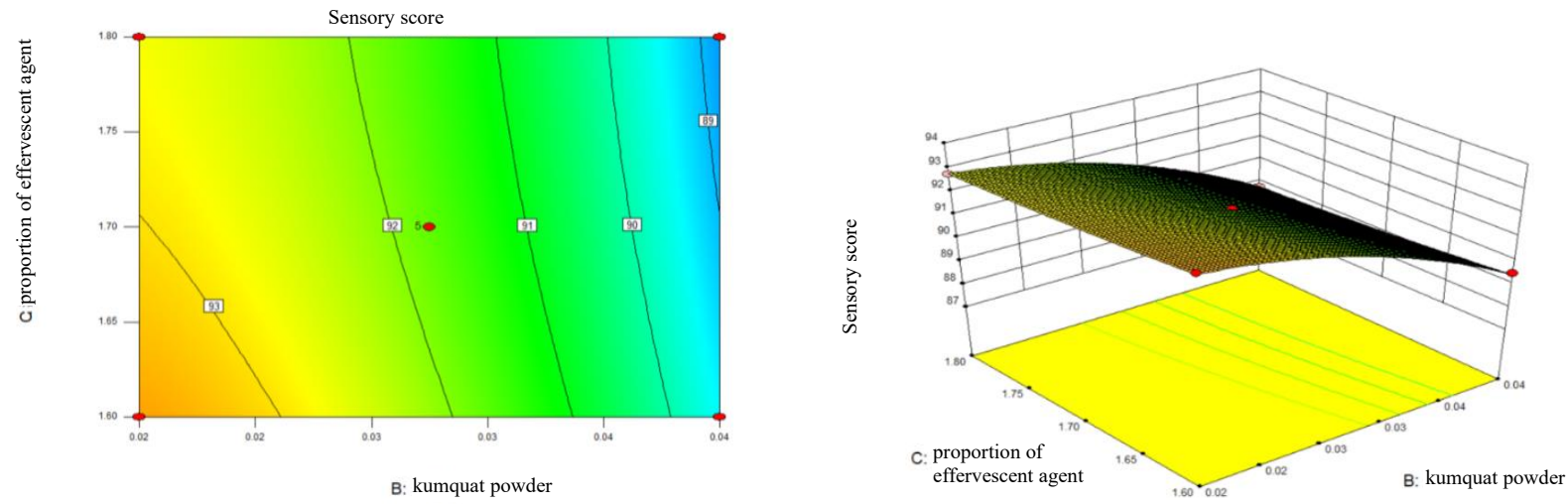

Figure 9 Contour and response surface diagrams of the interaction between the amount of kumquat powder added and the proportion of effervescent agent on the sensory score 

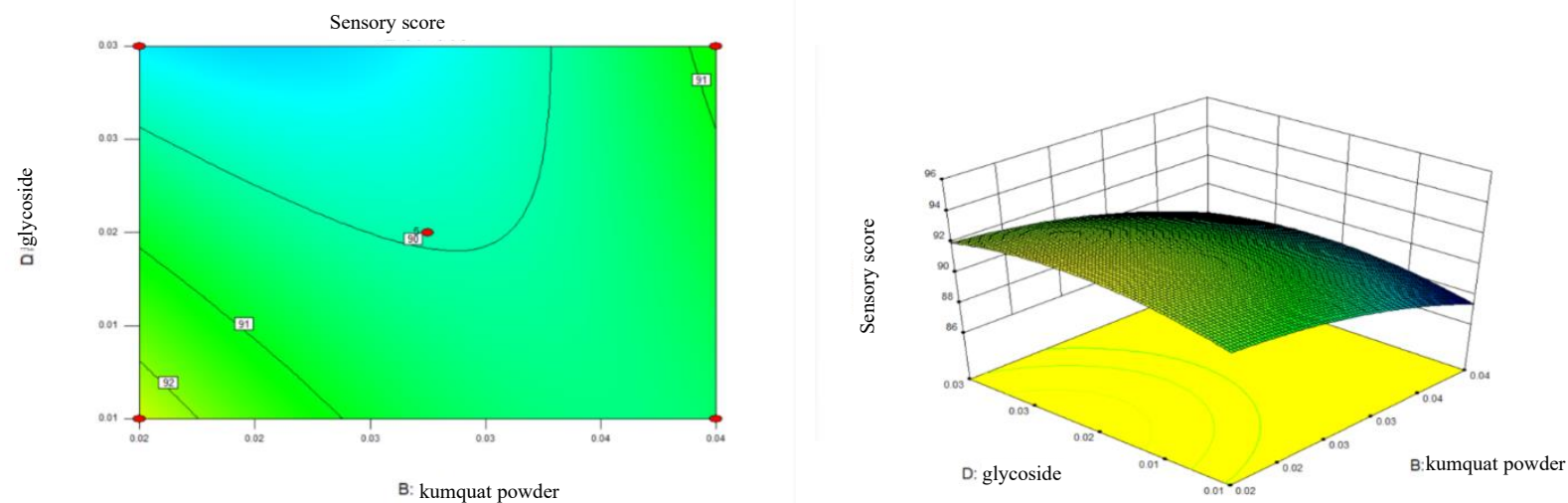

Figure 10 Contour and response surface diagrams of the interaction between the amount of kumquat powder added and mangosteen glycoside on the sensory score
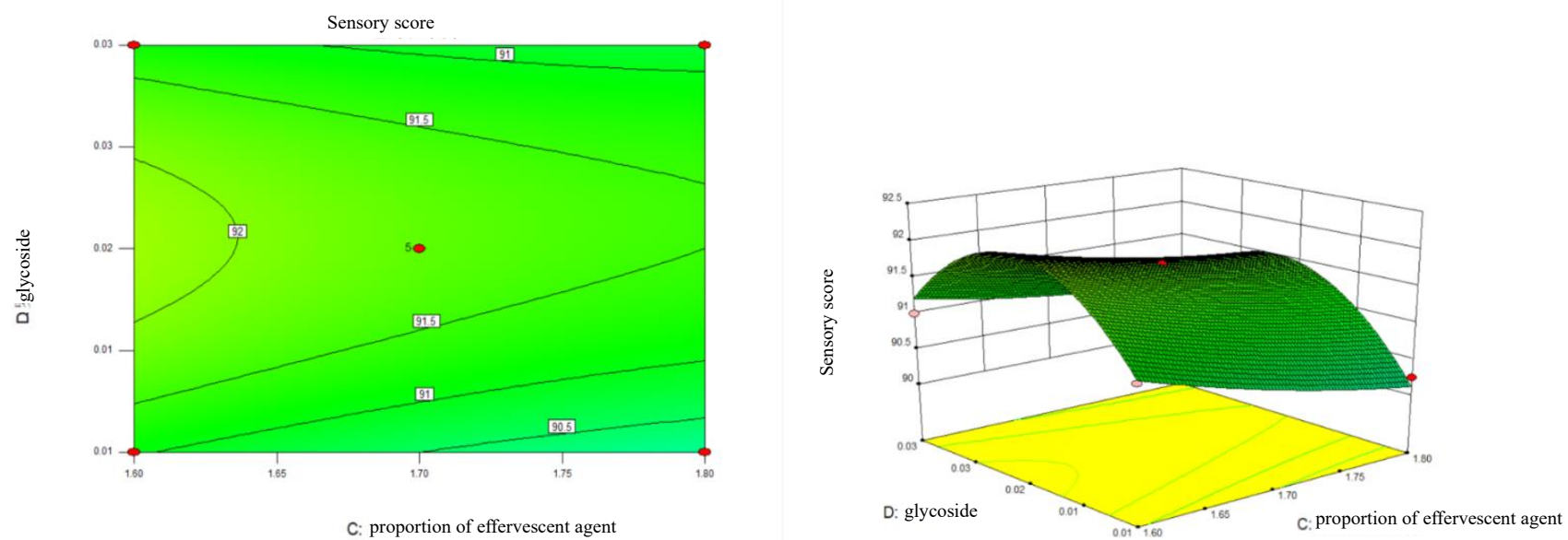

Figure 11 Contour plot and response surface plot of the effect of the interaction between the proportion of effervescent agent and the amount of mogroside on the sensory score

\subsection{Quality inspection of the finished product}

\subsubsection{The moisture absorption rate of the composite effervescent tablet}

Three groups of composite effervescent tablets selected form the response surface test $(\mathrm{m}$ sodium bicarbonate: $\mathrm{m}$ citric acid $=1: 1.6,1: 1.7,1: 1.8$ ) were tested for moisture absorption.

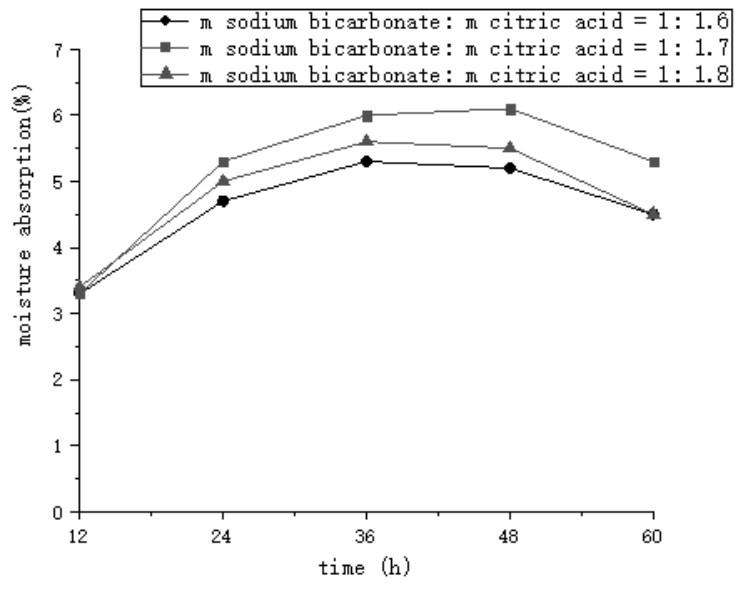

Figure 12 Detection of moisture absorption rate of composite effervescent tablets

It can be seen from the above figure that the optimal ratio of disintegrants obtained by the response surface test. $\mathrm{m}$ sodium bicarbonate: $\mathrm{m}$ citric acid $=1: 1.6$ has the lowest moisture absorption rate, which is most in line with the requirement of the low moisture absorption rate of the finished effervescent tablet. With the extension of the storage time of the finished tablets, the moisture absorption rate gradually increased, and the moisture 
absorption rate decreased after being placed for $48 \mathrm{~h}$. However, the foaming time of the effervescent tablet remains unchanged after moisture absorption, and there is no obvious change in the flavor, color, and precipitation of the effervescent tablet. Therefore, in the case of sealed packaging, although the effervescent tablet will have moisture absorption, it is not easy Deterioration and stable sensory conditions.

\subsubsection{Sensory score after moisture absorption}

The sensory score of the effervescent tablet after being placed for several days is shown in Table 4 as follows:

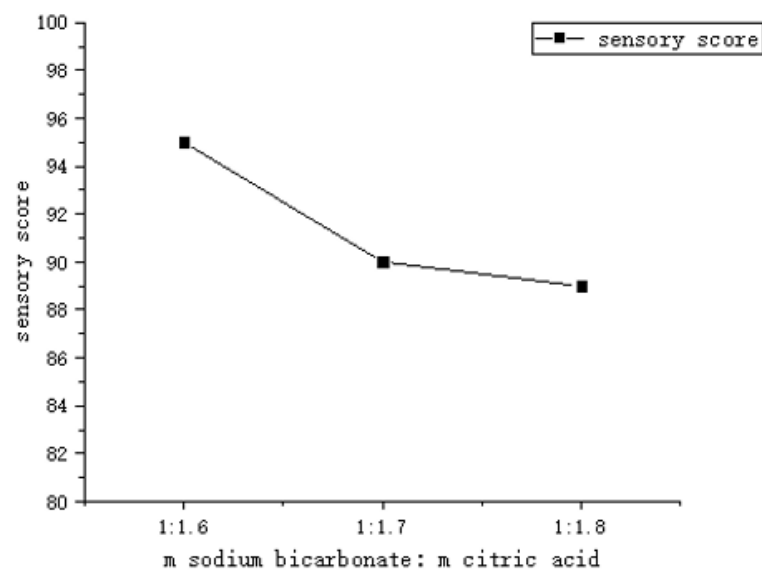

Figure 13 Sensory score after moisture absorption

It can be seen from the above figure that the optimal disintegrant ratio obtained by the response surface test $\mathrm{m}$ sodium bicarbonate: $\mathrm{m}$ citric acid $=1: 1.6$ group has the highest sensory score. As the moisture absorption rate increases, the color score decreases, mainly because the tablet absorbs water and causes the soup color to lighten, which affects the color, and the tablet water absorption has little effect on the tissue state, flavor and mouthfeel. It can be seen that this effervescent tablet also has a high sensory score after moisture absorption, which can be accepted by the public.

\section{Conclusions:}

The results showed that the optimized main formula of mangosteen compound effervescent tablets was: mangosteen powder $5.3 \%$, kumquat powder $1.3 \%$, mangosteen glycoside $1.3 \%$, effervescent disintegrant $90.7 \%$, of which citric acid: bicarbonate Sodium is 1.6:1. In this process, starch slurry and PEG-6000 are used as the granulation agent for the semi-dry tableting method. The composite effervescent tablet prepared after drying at $50^{\circ} \mathrm{C}$ for 3 hours is sweet and sour, rich in special aroma, short in foaming time, and has the lowest moisture absorption rate. The sensory score was 94.96 points

\section{References:}

1. Yiqing nong, Lin jiang, Haibin huang. Study on the extraction process of mogrosides from Luo Han Guo[J]. Shi Zhen Guo Yi Guo Yao(2007), 8(9): 2145-2165

2. Li li, Jinfeng sheng. Jin The nutritional value and comprehensive utilization status and prospects of tangerine[J]. Food Industry, ( 2015 ) , 36(9): 220-224

3. Hanyu hong, Bochuang feng, Zewei chen, et al. Kumquat Orange Flavored Wheat Craft Beer Process Research $[\mathrm{J}]$. Light Industry Science and Technology, ( 2019) , 35(5): 18-54

4. Research progress of Lijiao gao, Shangyang cheng, Long jin, Wenhua luo effervescent tablets in the food industry. Modern agricultural technology

5. Wenxin wang, Jing li, Wenkai zhou, et al. Preparation of blueberry effervescent tablets[J]. Food Research and Development, (2018), Volume 39(1): 60-64.

6. Zongxia yu. Development of Luo Han Guo black tea health drink [J]. Journal of Dalian University, (2019) , 40(3): 61-65

7. Jiangning gong, Jinhong wu, Zhengwu wang, Liling liao. Preparation of effervescent tablets of perilla extract[J]. Food Science, （2013）, 34 (6):280-284

8. Jinghui chen, Jingyu chen, Yiming zhu, et al. Preparation of Dendrobium candidum effervescent tablet and its antioxidant activity[J]. Food Science and Technology, (2019) , 44(5): 84-89

9. Qingxia wang, Jianying li, Hang yang. Preparation and quality evaluation of effervescent tablets of blackberry wolfberry extract[J]. Natural Product Research and Development, ( 2019) , 31(6): 1030-1037

10. Xiaojian luo, Hongliang xin, Xiaoyong rao, et al. Research progress of effervescent technology in pharmaceutical preparations [J]. Chinese Journal of Traditional Chinese Medicine, (2008), 33 (8): 973-976.

11. Xi yang, Haitao long, Haijun qiao.Preparation and process optimization of polysaccharide effervescent tablets of Jujube[J].Science and Technology of Food Industry, (2016),37(9):256-261

12. National Pharmacopoeia Commission. Pharmacopoeia of the People's Republic of China: Part II[M] .Beijing: Chemical Industry Press, (2000)

13. Xiaocui lin, Yuping zhu, Jinyin chen, etc. The research and development of small food products such as whole fruit navel orange effervescent tablets. ( 2018), 39 (18): 107-111

14. Fenfang liu, Yingqiu li. Optimization of the extraction process of mung bean protein by response surface methodology[J]. Journal of Light 
Industry, (2020), (2): 7-16.

15. MORITA K, NISHIJIMA Y, KADA T. Chemical nature of a desmutagenic factor from burdock
(Arctium lappa Linne)[J]. Agr Biol Chem, (1985),49(4):925-932. 